\title{
Pitting Corrosion of Bare Stainless Steel 304 under Chloride
} Solution Droplets

\author{
Bastian Maier* and G. S. Frankel**,z \\ Fontana Corrosion Center, The Ohio State University, Columbus, Ohio 43210, USA
}

Pitting corrosion behavior of stainless steel 304 (SS304) under droplets of chloride solution was investigated using a Kelvin probe (KP). Droplets of different volumes of $\mathrm{MgCl}_{2}$ solution were placed on the steel surface and exposed to a constant low relative humidity (RH). As the concentration increased during the exposure of the drop to low $\mathrm{RH}$, the open-circuit potential (OCP) and the shape change of the drop were monitored by the KP. Pit initiation was detected by a sudden decrease in the OCP. Pits initiated earlier under small droplets than under large drops. The chloride concentration at initiation was between 3.0 and $8.4 \mathrm{M}$ for droplets with a starting concentration of $0.88 \mathrm{M} \mathrm{Cl}^{-}$. The initiation concentration increased when the initial concentration of the droplet was higher. The anodic current demand of pits growing at the OCP decreased with time as did the available cathodic current. When the current demand exceeded the available cathodic current, the active pit area decreased. A mechanism for pit formation and growth under droplets of $\mathrm{MgCl}_{2}$ solution was proposed.

(C) 2010 The Electrochemical Society. [DOI: 10.1149/1.3467850] All rights reserved.

Manuscript submitted April 12, 2010; revised manuscript received June 29, 2010. Published August 9, 2010.

Stainless steels and other corrosion resistant alloys exhibit strong passivity but are susceptible to localized corrosion in the presence of chloride or other aggressive ions. ${ }^{1,2}$ These alloys are often immune to attack in dilute solutions, but breakdown can occur during atmospheric or alternate immersion conditions by the following scenario. A droplet of salt solution on the surface loses water due to a temperature increase or a decrease in relative humidity $(\mathrm{RH})$. The chloride concentration thereby increases until pitting corrosion initiates, which is accompanied by a sharp drop in the open-circuit potential (OCP) ${ }^{3,4}$

Tsutsumi et al. exposed stainless steel 304 (SS304) samples to seashore and rural atmospheres. ${ }^{5}$ No pits were found on samples in the rural area, while pitting initiated between 35 and $75 \% \mathrm{RH}$ in the marine environment. A humidity of $35 \%$ corresponds to a saturated magnesium chloride solution, and $75 \% \mathrm{RH}$ relates to $3 \mathrm{M} \mathrm{MgCl}_{2}$ (6 $\mathrm{M} \mathrm{Cl}^{-}$). According to these results, the chloride concentration for pit initiation under a thin electrolyte layer is around $6 \mathrm{M}$. This finding agrees with the results of other papers by the same authors. ${ }^{6,7}$ Tsutsumi et al. determined the onset of pitting, which is associated with a critical chloride concentration, from the sudden drop in the OCP of the stainless steel electrode measured vs an $\mathrm{Ag} / \mathrm{AgCl}$ reference electrode (RE). ${ }^{7}$ The $\mathrm{Cl}^{-}$concentration of the thin electrolyte layer was controlled by varying the RH. The initiation chloride concentration increased with increasing drying rate and with decreasing amount of salt on the surface. The same researchers also studied the influence of electrolyte drop size on the occurrence of the pitting and concluded that pitting is less likely under drops with a small diameter $(<5 \mathrm{~mm})$ due to a small cathode area. ${ }^{6,8}$

The placement of the RE relative to the sample is complicated for a thin-film electrolyte. Vera Cruz et al. used an agar-filled hole coplanar with the sample surface to provide ionic connection to a remote RE. ${ }^{3}$ This approach suffers from problems associated with nonuniform current distribution for measurements in which the potential is applied. 9,10 The problem of introducing an RE into the thin water layer responsible for atmospheric corrosion was solved by Stratmann and Streckel who demonstrated that a Kelvin probe (KP) vibrating above a sample provides a measure of the corrosion potential. ${ }^{11-13}$ Some KPs can control the distance between the tip and the sample, allowing simultaneous tracking of the sample topography or measurement of the thickness of an electrolyte layer as it dries.

In this study, the pitting corrosion behavior of SS304 under an electrolyte droplet was investigated using a height-controlled KP. It was thereby possible to determine the pit initiation time from the

\footnotetext{
* Electrochemical Society Student Member.

** Electrochemical Society Fellow.

${ }^{z}$ E-mail: frankel.10@osu.edu
}

corrosion potential and the chloride concentration at initiation from the progression of the drop dimensions during drying.

\section{Experimental}

Pitting measurements.-Commercial grade SS304 plates (15 $\times 15 \times 1 \mathrm{~mm}$ ) embedded in epoxy resin were polished to 4000 grit and rinsed with ethanol. For the KP experiments, a micropipette was used to place a drop of $\mathrm{MgCl}_{2}$ on the sample. The $\mathrm{MgCl}_{2}$ solution had a concentration of 0.44 or $2.50 \mathrm{M}$. Three different volumes of $0.44 \mathrm{M} \mathrm{MgCl}_{2}$ solution were used: 2,4 , and $6 \mu \mathrm{L}$.

The KP was first calibrated with $\mathrm{Cu} / \mathrm{CuSO}_{4}$. The $\mathrm{MgCl}_{2}$ droplet was then applied to the surface of the sample, which was immediately placed in the KP chamber $(21 \times 19 \times 21 \mathrm{~cm})$. The KP tip was positioned on top of the drop, and the potential was monitored as a function of time. The KP tip was a type 304 stainless steel wire sharpened to a diameter of $189 \mu \mathrm{m}$. The airtight chamber door was closed, and the chamber was purged continuously with air of constant low RH (33-34\%), which was achieved by prebubbling the air through several columns containing saturated $\mathrm{MgCl}_{2}$ solution. The solution drop on the sample surface with relatively low chloride concentration initially was not in equilibrium with the low RH in the air flowing through the chamber, causing the drop to lose water from evaporation and to decrease in height. The operation principles of the KP instrument (K\&M SoftControl, Düsseldorf, Germany) were described previously. ${ }^{14}$ It has the ability to maintain a constant separation between the tip and the solution surface and so can track the drop height as well as the sample corrosion potential as a function of time (Fig. 1). When the $\mathrm{MgCl}_{2}$ solution in the drop was in equilibrium with the $\mathrm{RH}$ in the chamber as indicated by no further change in drop height, the KP was used to map the drop topography to determine the final height and radius of the drop. The experiments were replicated many times (6-33) to develop sufficient statistics to discriminate the results.

For comparison, samples with a surface area of $\sim 72 \mathrm{~mm}^{2}$ were also immersed in bulk solutions with concentrations of 2.5, 3.0, 3.5, 4.0, 4.5, or 4.9 (saturated) $\mathrm{M} \mathrm{MgCl}_{2}$ for $22 \mathrm{~h}$.

Determination of dissolved oxygen in $\mathrm{MgCl}_{2}$ solutions. - The oxygen content of different $\mathrm{MgCl}_{2}$ solutions equilibrated with air was determined by using the dissolved oxygen test kit model O-12 from CHEMetrics. Solutions with a volume of $100 \mathrm{~mL}$ and three different $\mathrm{MgCl}_{2}$ concentrations were prepared: 0.42, 2.5, and 5.7 M. The test kit utilizes a glass ampule with Rhodazine D. Upon breaking the tip while submersed, the solution was sucked in. The Rhodazine D compound reacted with oxygen, leading to a blue coloration. The strength of the blue coloration depended on the oxygen concentration. The oxygen content of deionized (DI) water was measured as well. 


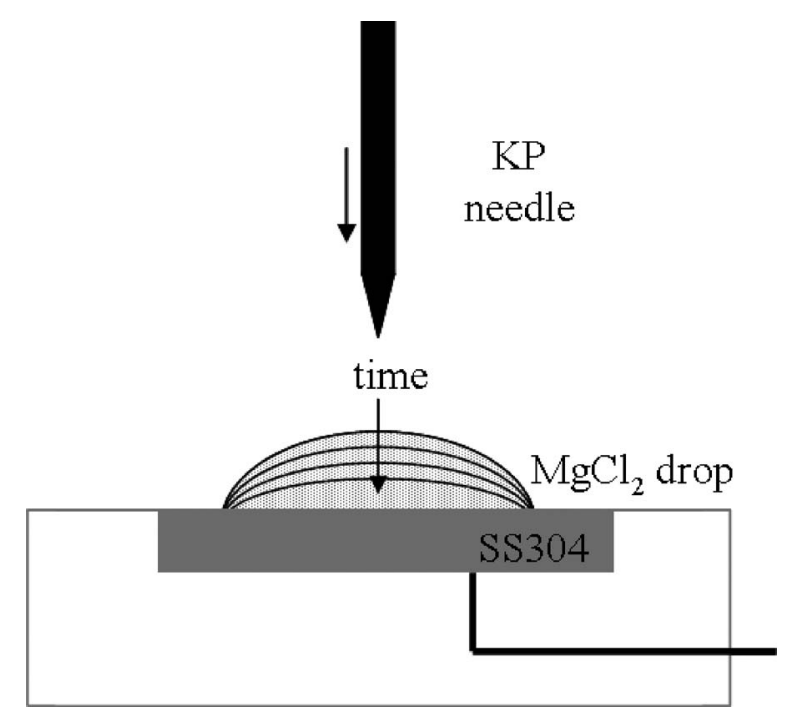

Figure 1. Experimental setup for drying experiments on SS304.

Determination of pit dimensions. - To determine the anodic current for a growing pit, pits were grown for different time periods, as indicated by the time elapsed after the characteristic potential drop. The samples were then quickly removed from the KP chamber and rinsed with DI water. The volume and active area of the pit at the end of the exposure period were determined. A high power light microscope and imaging software was used to determine the active pit area. The volume was obtained by scanning the pits with an optical profilometer (Vecco Wyko NT9000) and processing the data with the associated software package. Droplet volumes of 2 and $4 \mu \mathrm{L}$ of $0.44 \mathrm{M} \mathrm{MgCl}_{2}$ solution were used. Assuming stoichiometric dissolution of $\mathrm{Fe}, \mathrm{Cr}$, and $\mathrm{Ni}$ and a density of $7.93 \mathrm{~g} / \mathrm{cm}^{3}$ of SS304, the current as the derivative of the charge can be calculated from the pit volumes for different pitting times.

\section{Results}

Figure 2 shows a typical OCP transient during drying of a $\mathrm{MgCl}_{2}$ droplet on an SS304 sample. The potential dropped by tens of millivolts, stabilized, and then exhibited a precipitous decrease. This decrease is considered to be associated with the initiation of pitting.

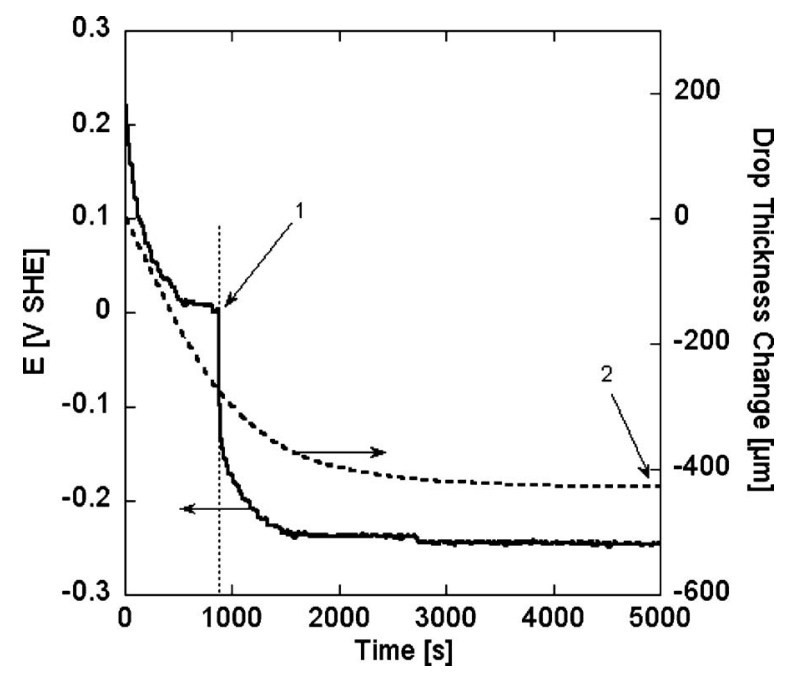

Figure 2. Change in the electrolyte thickness and OCP as a function of time. Point 1 shows the pit initiation time. Point 2 represents the equilibration of the drop with the environment.
The form of this potential transient is identical to that observed using other techniques. ${ }^{3}$ Every sample exposed in this fashion exhibited a similar potential drop. Furthermore, upon examination of the surface afterwards, every sample contained a single pit that was randomly located relative to the droplet (i.e., pits were found at the center and toward the edge of the drop on different samples). More details on the pits are given below.

Also shown in Fig. 2 is the drop thickness or height change at the center of the drop. At the beginning of exposure, the drop thickness decreased linearly with time due to evaporation of water in the low $\mathrm{RH}$ environment. The evaporation rate gradually decreased until the height did not change anymore, at which point the drop was assumed to be in equilibrium with the $\mathrm{RH}$ in the chamber. At this point, the shape of the drop was determined by scanning across the entire drop surface with the KP tip. An example of the final drop shape as revealed by the KP scan is shown in Fig. 3.

A graphical software package was used to display the drop shape and to determine the radius $(a)$ and thickness of the drop $(h)$. With these data, the volume $(V)$ of the drop as a function of time during drying was calculated from the thickness assuming that the drop resembled a spherical cap and that drop radius $a$ was constant

$$
V(t)=\frac{1}{6} \pi h(t)\left[3 a^{2}+h(t)^{2}\right]
$$

The assumption of constant radius with time was based on visual observation during drying and agrees with a similar study. ${ }^{6}$ By knowing the initial volume $\left(V_{0}\right)$ and the concentration of the drop $\left(C_{0}\right)$ and calculating the volume at time $t\left(V_{\mathrm{t}}\right)$, the chloride concentration at any time can be determined from

$$
C_{\mathrm{t}}=C_{0}\left(V_{0} / V_{\mathrm{t}}\right)
$$

The chloride concentration at the time of pit initiation was obtained in this fashion using the droplet volume at the time of pit initiation.

Three different drop volumes of $0.44 \mathrm{M} \mathrm{MgCl}_{2}$ solution (2, 4, and $6 \mu \mathrm{L}$ ) were used to investigate the relation between the drop size and the initiation chloride concentration, as well as pit initiation time. The final drop height exhibited considerable variability, but tended to increase with increasing initial volume. However, the drop area scaled linearly with drop volume. The time for pit initiation was lower for $2 \mu \mathrm{L}$ drops, and no significant difference was observed for 4 and $6 \mu \mathrm{L}$ drops (Fig. 4).

The calculated chloride concentration at the time of pit initiation varied from 3.0 to $8.4 \mathrm{M}$ (Fig. 5). Other authors reported a range of 4.9-6.2 M. ${ }^{6}$ It is apparent from Fig. 5 that the median initiation concentration decreases with increasing initial drop volume. The probability of pitting at a lower chloride concentration is higher under a large drop than under a small drop.

The final drop height exhibited considerable variability, and there was no relationship between the final drop height and the critical chloride concentration for pitting.

Figure 6 shows a distribution plot of the initiation chloride concentration for pitting of SS304 exposed to droplets with two different initial $\mathrm{MgCl}_{2}$ concentrations $(0.44$ and $2.50 \mathrm{M}$ ), which equates to initial chloride concentrations of 0.88 and $5.0 \mathrm{M}$, respectively. For a starting chloride concentration of $0.88 \mathrm{M}$, pits initiated at concentrations of as low as $3.5 \mathrm{M}$, and the mean pit initiation concentration was $\sim 6 \mathrm{M}$. However, for a starting concentration of $5.0 \mathrm{M}$, the lowest pit initiation concentration was $6.5 \mathrm{M}$. It seems that the initiation time is influenced strongly by the time needed for the breakdown of the passive film as well as achieving a sufficiently high chloride concentration in the droplet. The wide range of initiation chloride concentrations suggests that there is no single critical chloride concentration for pit initiation.

Pit morphology.- Figure 7 shows scanning electron microscope (SEM) images of pits grown for different amounts of time. There was always only one pit under each droplet, and the pit site was not at a specific location. The drop diameters ranged between 3 and 4 


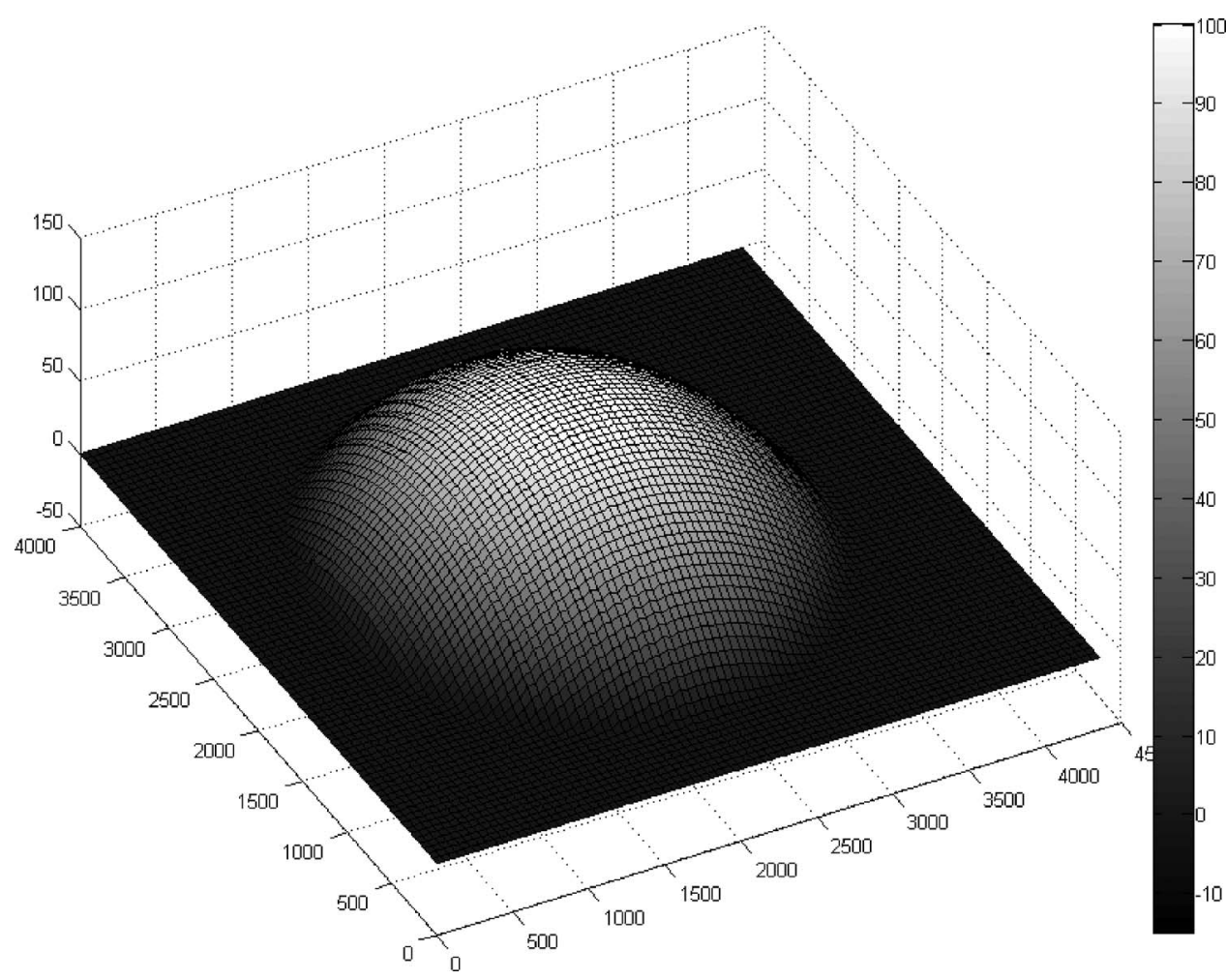

Figure 3. Topographic map of a droplet after equilibration with the low RH environment. The units on the axes and color scale bar are in micrometers. mm depending on the initial volume and were, therefore, approximately 50 times larger than the pit diameters, which were on the order of $70-120 \mu \mathrm{m}$.

The pits in Fig. 7 are seen to be almost perfectly circular, particularly for those grown for only a short period. Figure 7a shows a pit that grew for $1.6 \mathrm{~min}$ after initiation. In the center of the pit, there was a small hole that was likely the initiation site. Other researchers saw similar features and assumed they were associated with MnS inclusions, ${ }^{6,8}$ which are well-known initiation sites for pitting corrosion on stainless steel. ${ }^{15-17}$ The pits grew uniformly in all directions from the initiating defect resulting in circles. The pits started out as a shallow "V" shape of depth $\sim 950 \mathrm{~nm}$ after $1.6 \mathrm{~min}$

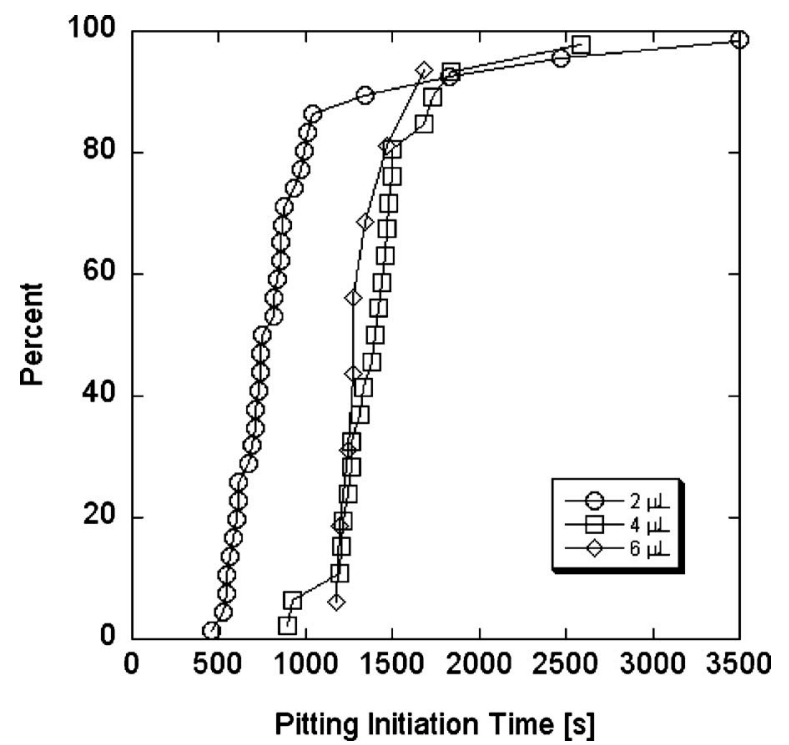

Figure 4. Distribution plot of pitting initiation times for the three different initial drop volumes. with the defect in the center, as shown in Fig. 8a. They then developed into a "U" shape of depth $\sim 1500 \mathrm{~nm}$ after 39 min (Fig. 8b). After some time, the pits stopped growing in the lateral direction and then grew in depth but only in a certain area forming an earshaped hole, as can be seen in Fig. 7b-d. Further discussion of the ear formation is given below.

The pit volume and active pit area were determined with an atomic force microscope, an optical microscope, and imaging software. Pits were allowed to grow for various times after initiation and then removed from the KP chamber, rinsed, and dried. The charge associated with pit volume was calculated assuming congruent dis-

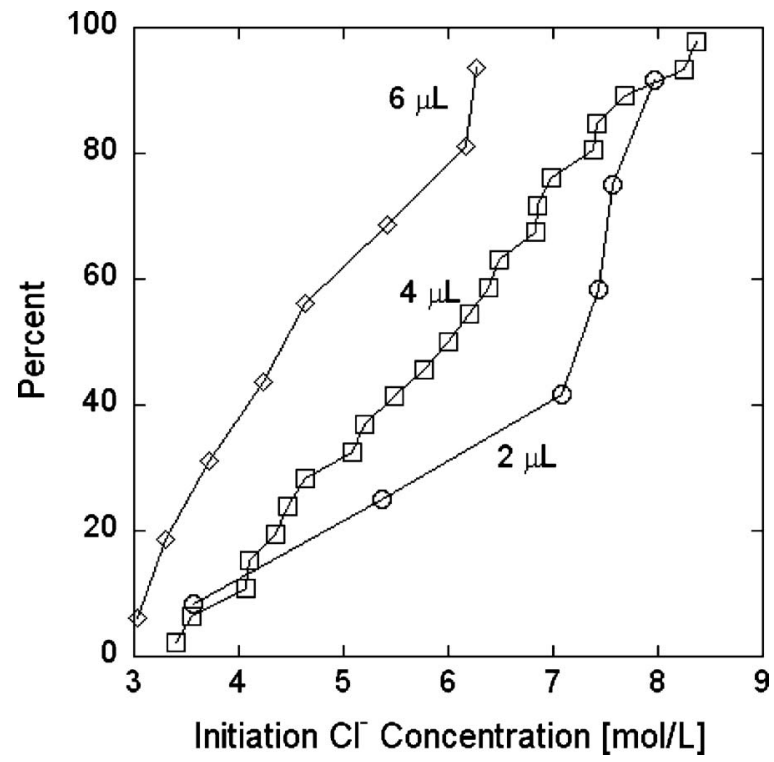

Figure 5. Distribution plot of initiation chloride concentration for the three different initial drop volumes. 


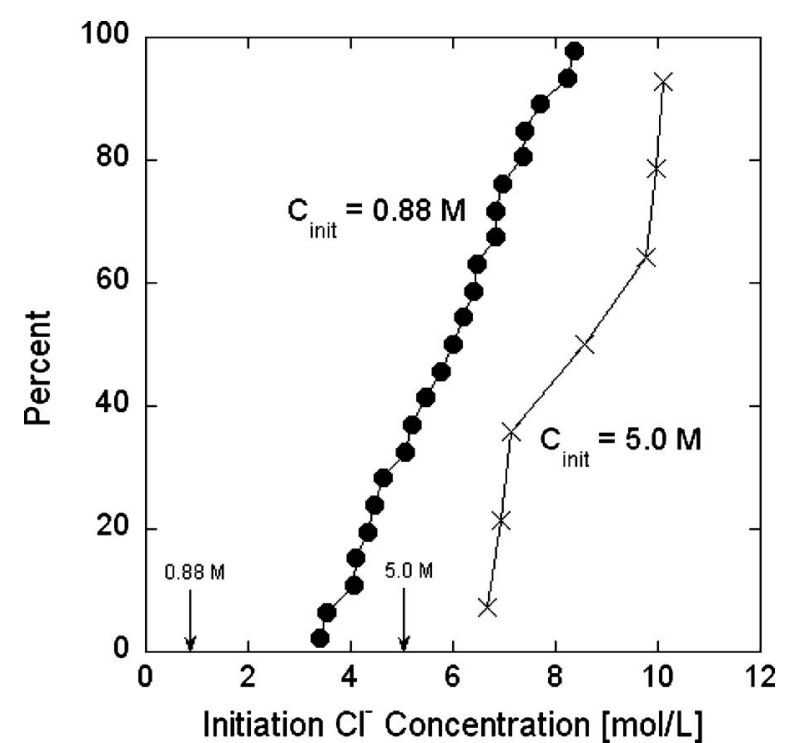

Figure 6. Initiation chloride concentration for pitting of $4 \mu \mathrm{L}$ droplets of 0.44 and $2.50 \mathrm{M} \mathrm{MgCl}_{2}$ solution on SS304.

solution of SS304 and is shown in Fig. 9 as a function of growth time. For the determination of the active pit area, it was assumed that the entire circular disk was active at the beginning, and later on, only the ear-shaped region was active, as shown in Fig. 10. The active areas of pits grown for various times under $2 \mu \mathrm{L}$ droplets are shown in Fig. 11 as a function of growth time. No clear trend can be seen. Similar results were obtained for pits under droplets with a volume of $4 \mu \mathrm{L}$.

\section{Discussion}

Pitting under droplets. - As shown in Fig. 4, the time needed for pit initiation was lower for $2 \mu \mathrm{L}$ drops than for 4 and $6 \mu \mathrm{L}$ drops. The volume and therefore the chloride concentration at every time during the experiment can be calculated by Eq. 1 and 2. Such calculations show that drops with a volume of $2 \mu \mathrm{L}$ have a steeper increase in chloride concentration than drops of 4 and $6 \mu \mathrm{L}$ (Fig. 12). As a result of the faster decrease in volume and increase in chloride concentration for the smallest drop size, higher chloride concentrations are reached quicker and pitting initiates earlier. The higher drying rate probably originates from a larger surface area to volume ratio of the $2 \mu \mathrm{L}$ droplet in comparison to 4 and $6 \mu \mathrm{L}$. Assuming the drop resembles a spherical cap, the surface area is given by

$$
S=\pi\left(a^{2}+h^{2}\right)
$$

where $a$ is the drop radius and $h$ is the drop height. The surface to volume ratio thus has an inverse dependence on height. Drops of volume 4 and $6 \mu \mathrm{L}$ show similar drying rates. The RH at the beginning of the experiments was not well controlled because the chamber door of the KP was open during the insertion of the sample. As a result, around $5 \mathrm{~min}$ were required to achieve a constant $\mathrm{RH}$ of $33-34 \%$. However, the solution height as a function of time in Fig. 2 does not show a different slope at the beginning and after 5 min. Thus, lack of RH control at the beginning of the experiment did not affect the initial drying rate.

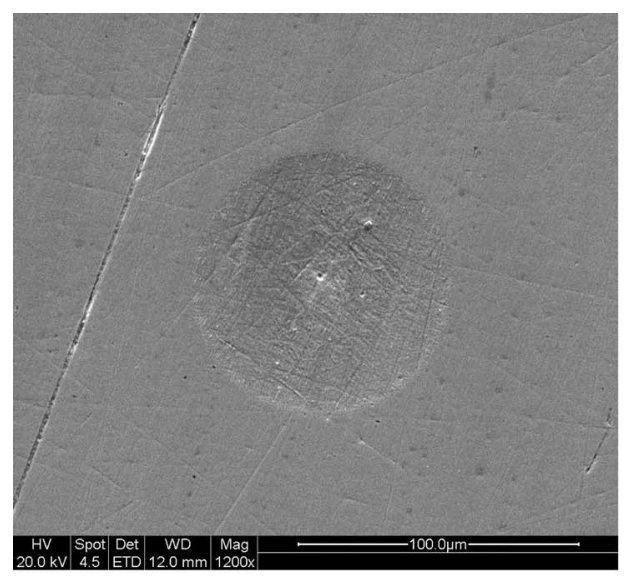

(a)

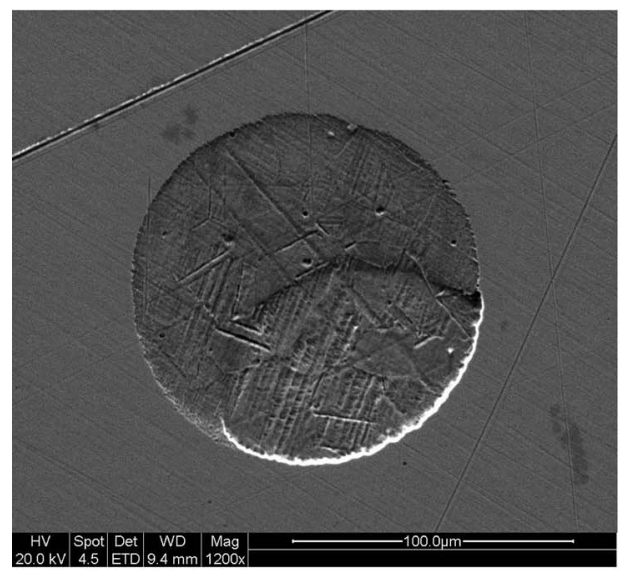

(c)

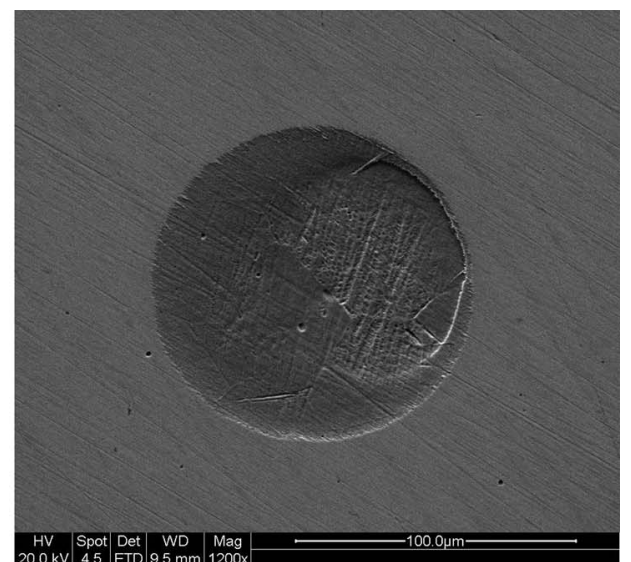

(b)

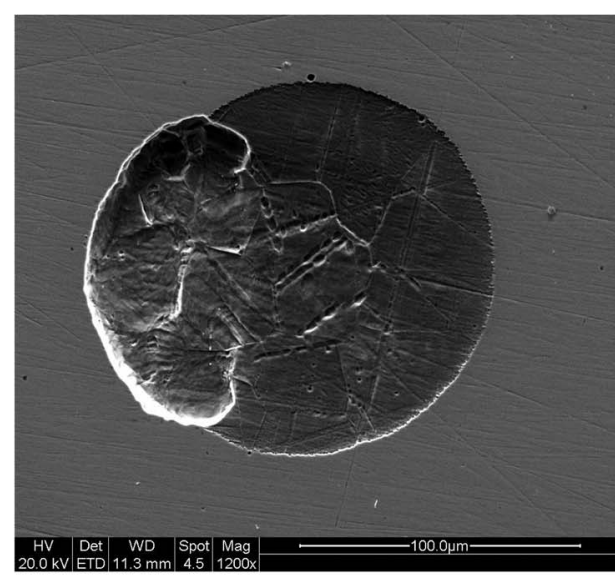

(d)
Figure 7. Pit morphology of pit growing for (a) 9.2, (b) 138.4 , (c) 247.8 , and (d) $858.3 \mathrm{~min}$ under droplets of $4 \mu \mathrm{L}$. 


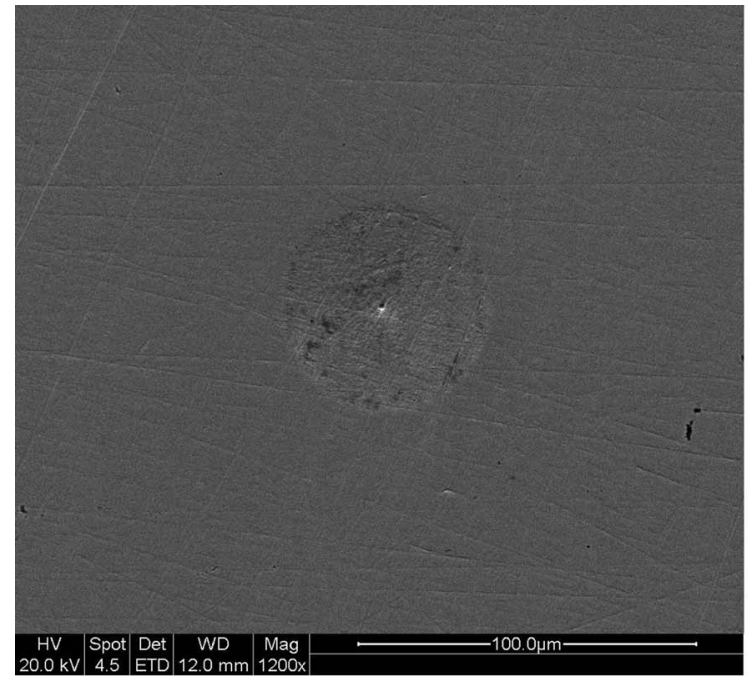

(a)

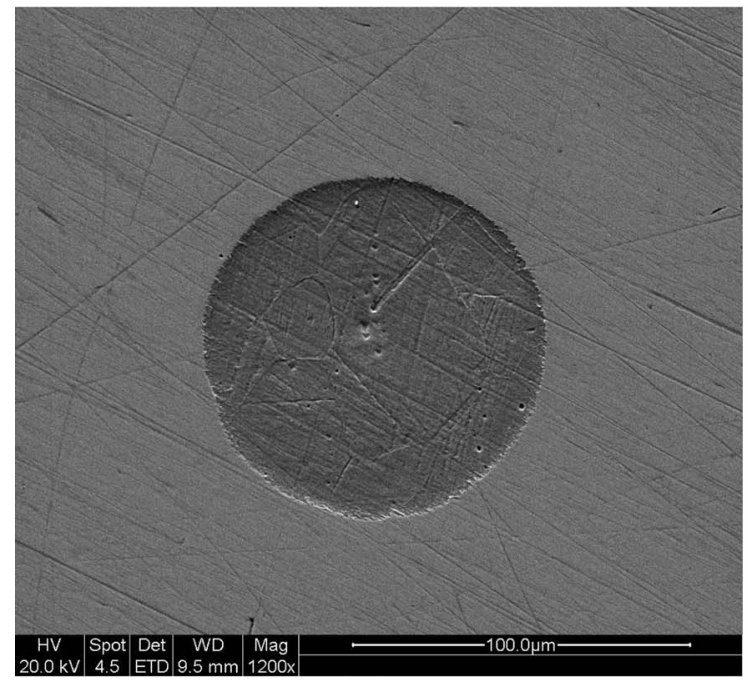

(b)

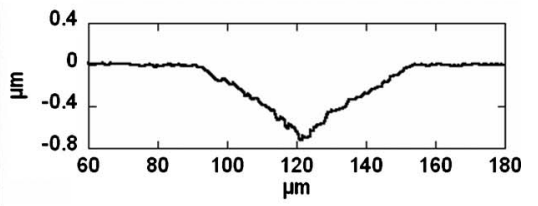

Figure 8. SEM picture and corresponding profilometer depth profile of two different pits growing for (a) 1.6 and (b) $38.7 \mathrm{~min}$.

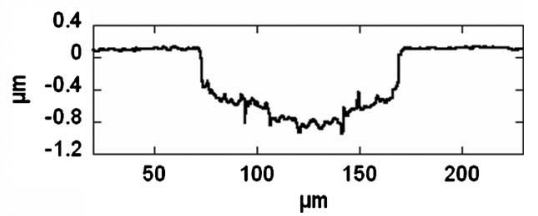

Figure 12 also shows that the final chloride concentration in equilibrium with the environment was $\sim 8 \mathrm{M}$. The $\mathrm{RH}$ in the cham-

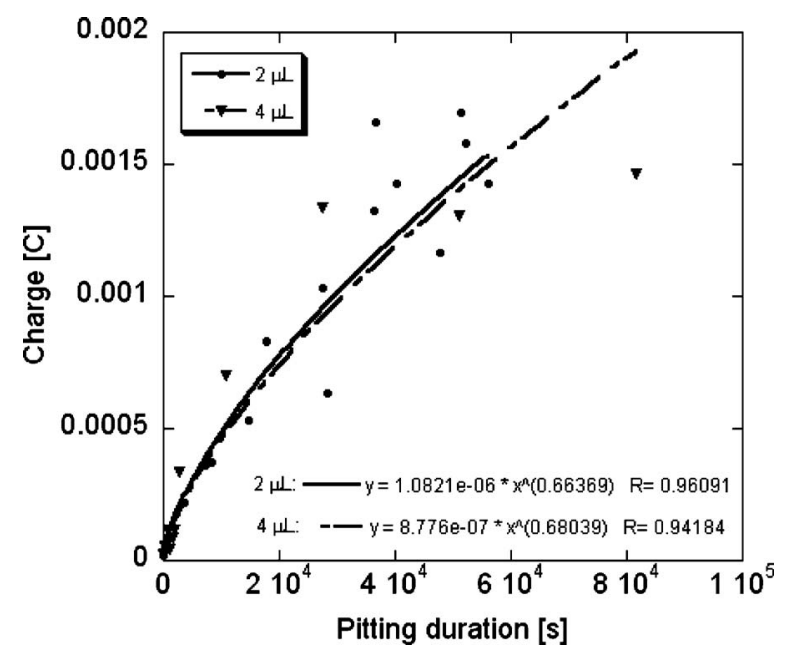

Figure 9. Charge of pits growing for different amounts of time under droplets of 2 and $4 \mu \mathrm{L}$. ber was controlled by presaturating the purge air using a series of wash bottles filled with saturated pure $\mathrm{MgCl}_{2}$ solution. The concentration of the saturated pure $\mathrm{MgCl}_{2}$ solution was calculated to be 4.9 $\mathrm{M} \mathrm{MgCl}_{2}$ or $9.8 \mathrm{M} \mathrm{Cl}^{-}$based on the solubility of $\mathrm{MgCl}_{2}$ in water $\left(54.3 \mathrm{~g} \mathrm{MgCl}_{2} / 100 \mathrm{~mL}\right.$ water $\left.{ }^{18}\right)$ and the measured density of the saturated solution $(1.33 \mathrm{~g} / \mathrm{mL})$. The concentration of a pure $\mathrm{MgCl}_{2}$ droplet in equilibrium with the test humidity was measured by placing a $0.44 \mathrm{M} \mathrm{MgCl}_{2}$ drop on a gold substrate and mapping the steady-state volume with the KP. The chloride concentration for a droplet on $\mathrm{Au}$ at equilibrium was $9.6 \mathrm{M}$, which closely agrees with the calculated saturation concentration. The lower concentration of chloride for the droplet on stainless steel indicates that the products of the corrosion process influenced the equilibrium between the concentrated salt solution and the humidity in the environment. It is likely that the critical humidity of the salts in the droplet after the corrosion process was lower than that for the pure $\mathrm{MgCl}_{2}$ because, for example, ferrous chloride has a critical RH of $\sim 20 \% .^{19,20}$ As discussed below, the other salts in the solution might also affect the physical properties of the solution.

Figure 5 shows that the chloride concentration at the time of pit initiation varied from 3.0 to $8.4 \mathrm{M}$ and that the initiation critical concentration decreased with increasing initial drop volume. The wide range of initiation chloride concentrations suggests that there is no single critical chloride concentration for pit initiation. On the other hand, the increase in chloride concentration associated with 


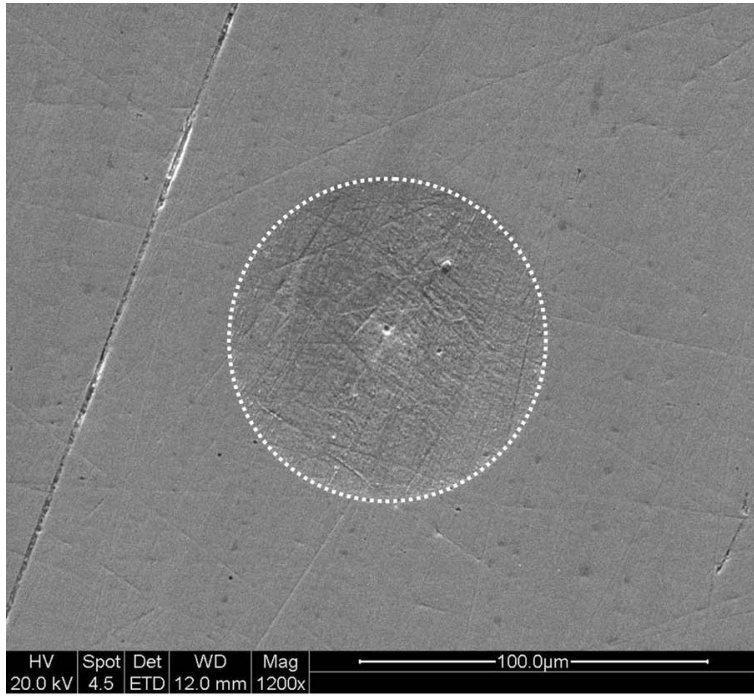

(a)

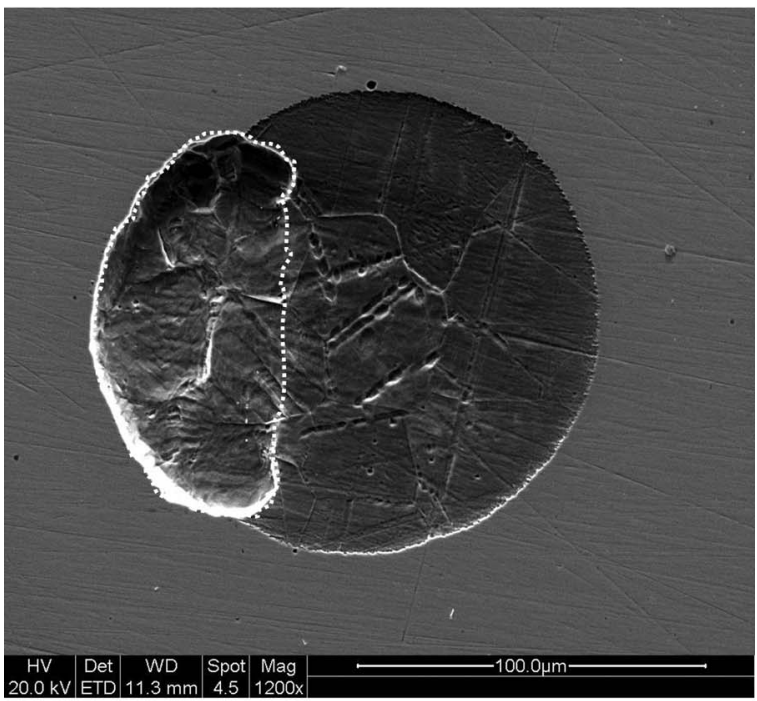

(b)

Figure 10. Area within the white dashed line is defined as active pit area. (a) 9.2 and (b) $858 \mathrm{~min}$.

drying was clearly critical to the stability of pits, as shown in an experiment where the RH was increased from 34 to $90 \%$ after the potential drop associated with pit initiation was observed, as shown in Fig. 13. The droplet height immediately increased, indicating that the higher humidity caused the droplet to take up water, which resulted in dilution of the dissolved salts. Within $\sim 100 \mathrm{~s}$, the potential started increasing, eventually almost reaching the value observed before pit initiation. This increase in potential indicates that the pit repassivated as a result of the dilution of the droplet solution.

Simple immersion experiments in bulk solutions with different chloride concentrations were performed for comparison with the experiments under thin droplets. No corrosion of any form was observed on the sample immersed in bulk 5.0 M chloride solution (2.5 $\mathrm{M} \mathrm{MgCl}_{2}$ ). For samples immersed in bulk solutions with 6.0 and 7.0 $\mathrm{M}$ chloride concentration, crevice corrosion was observed at one site along the epoxy mount edge. The samples immersed in 8.0, 9.0, and 9.8 (saturated) $\mathrm{M}$ chloride solutions exhibited pitting and not crevice corrosion. These concentrations are in the same range as the critical chloride concentrations observed for pitting in the thin droplet. However, direct comparison of the two environments is complicated. A drying droplet is very dynamic in that the chloride and

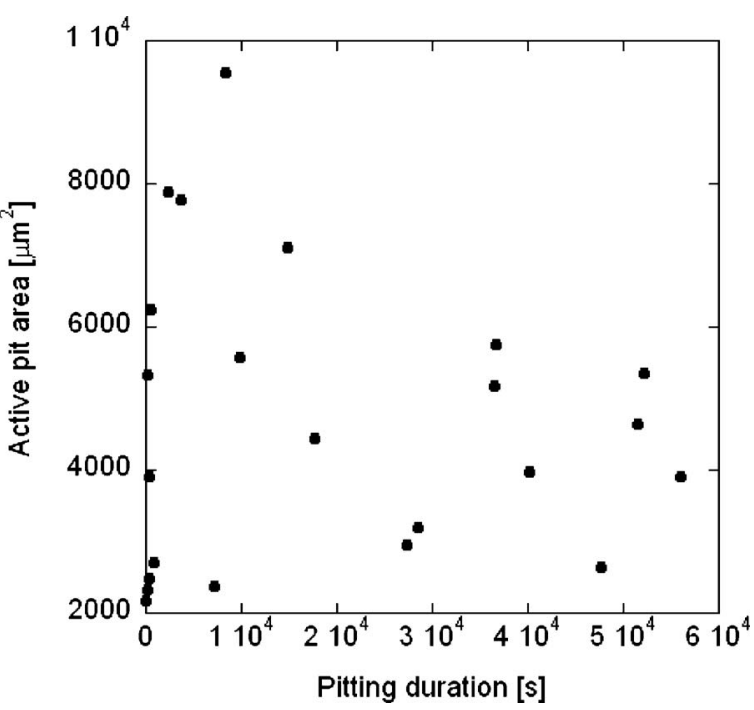

Figure 11. Active pit area as a function of pitting duration for pits under droplets with an initial volume of $2 \mu \mathrm{L}$.

oxygen concentrations and the viscosity are changing until saturation occurs. During the bulk experiments, these parameters remain constant. Figure 6 shows that, by just increasing the initial chloride concentration of an electrolyte drop, the pitting initiation concentration distribution increased to higher values.

The effect of droplet size shown in Fig. 4 can partly be explained by the fact that a drop of larger radius has a higher probability of covering an area that includes a more susceptible defect, such as an $\mathrm{MnS}$ inclusion, so pitting has a higher chance of initiation at a lower chloride concentration. No direct evidence linking MnS inclusions to pit initiation sites was found. For instance, energy-dispersive spectroscopy (EDS) analysis in an SEM found no evidence of surface contamination by S. However, the amount of S associated with a single inclusion is likely too small to be observed by EDS. The distribution of susceptible sites was studied using a sample that was polished to $0.05 \mu \mathrm{m}$ and then etched in $10 \% \mathrm{FeCl}_{3}$. Figure 14 is an optical micrograph of an area after etching. The dark spots are as-

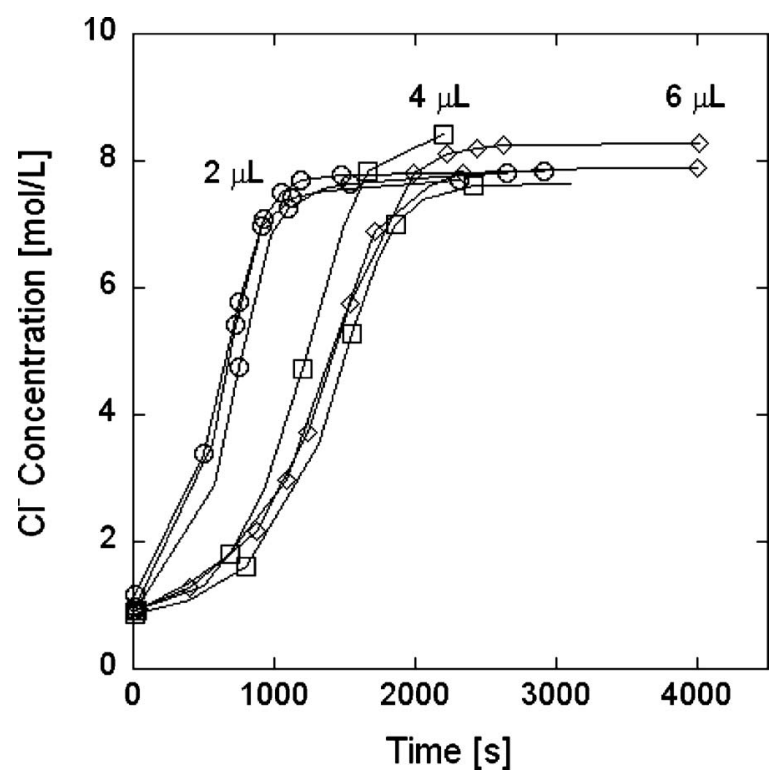

Figure 12. Drying rate represented by showing the chloride concentration of the drop vs time. 


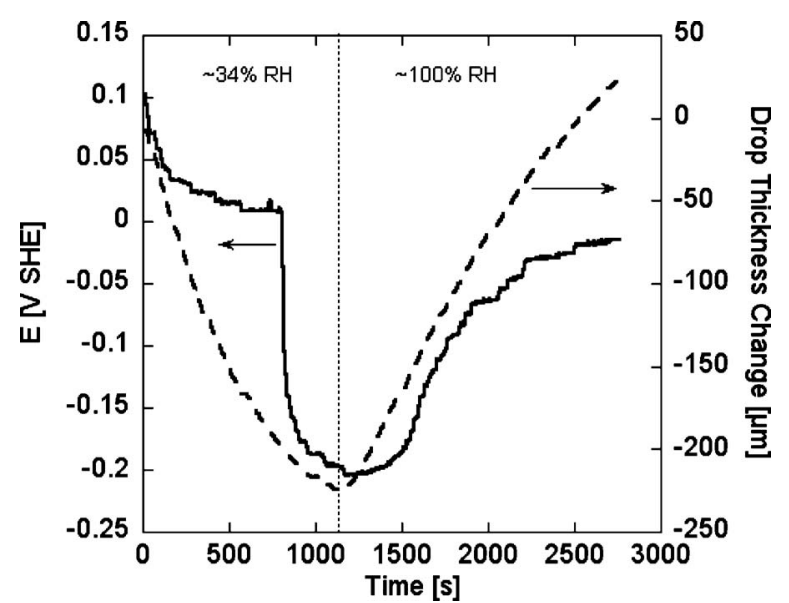

Figure 13. Change in the electrolyte thickness and OCP as a function of time of a droplet with initial concentration of $2.5 \mathrm{M} \mathrm{MgCl}_{2}$. After pit initiation, $\mathrm{RH}$ was increased from 34 to $\sim 100 \%$.

sumed to be $\mathrm{MnS}$ inclusions that were dissolved in the $\mathrm{FeCl}_{3}$ solution. The field of view in these images is approximately equal to the size of the pits formed in the concentrated $\mathrm{MgCl}_{2}$ solution, showing that there are many $\mathrm{MnS}$ inclusions available in the area of a droplet to act as initiation sites. The pit initiates at the most susceptible site, and the rest of the area is, apparently, cathodically protected from attack.

Another issue to consider is the effect of the droplet size on the available cathodic current. Tsutsumi et al. suggested that there is a decreased likelihood of pitting under small drops because the smaller exposed area supports a less cathodic current. ${ }^{6}$ Stable pit growth at open circuit requires sufficient cathodic reaction to meet the anodic current demand, which typically increases with time as a pit increases in size even though the rate of growth decreases. ${ }^{21,22}$ For this near neutral chloride solution, the dominant cathodic reaction is oxygen reduction. Therefore, continued pit growth requires a sufficient supply of oxygen to support the anodic current needed to sustain the concentrated local environment necessary for pit stability. Assuming that the oxygen reduction reaction is diffusion limited, the available cathodic current is given by

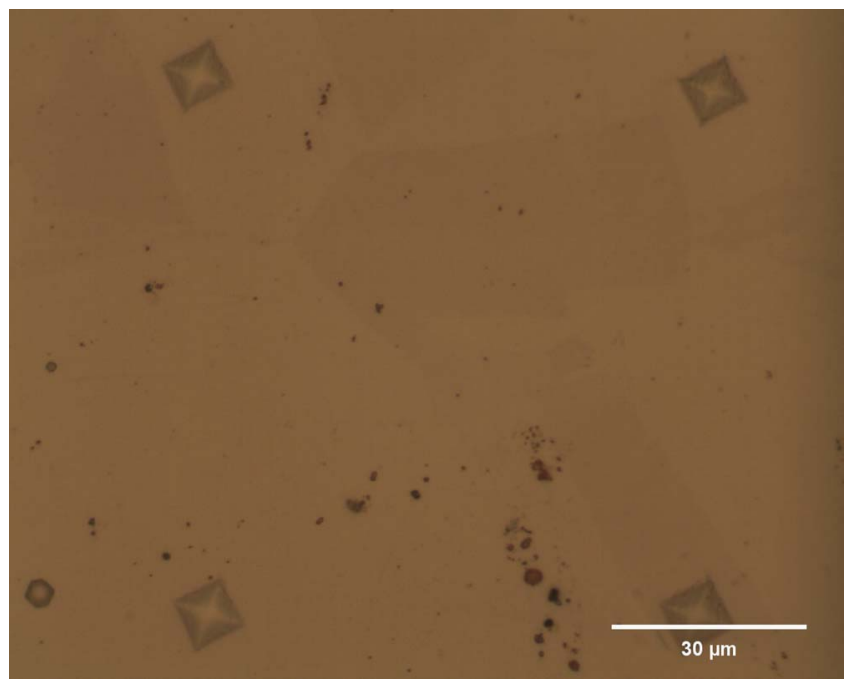

Figure 14. (Color online) SS304 surface after immersion in $10 \% \mathrm{FeCl}_{3}$ for $20 \mathrm{~min}$. The three diamond shapes are pyramidal indentations used as fiducial marks.

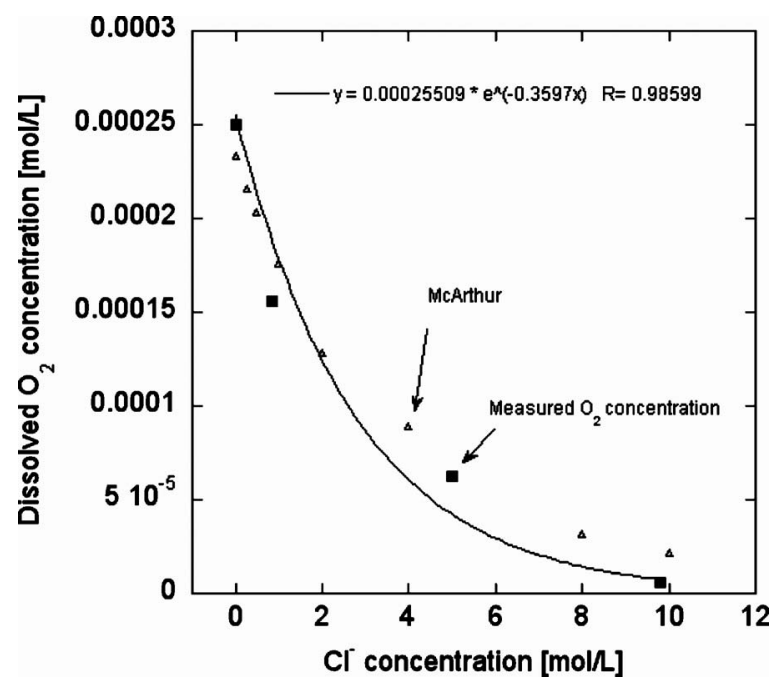

Figure 15. Concentration change in dissolved oxygen in $\mathrm{MgCl}_{2}$ solution as a function of chloride concentration. The plot shows measured data and data obtained by MacArthur. ${ }^{23}$

$$
I_{\text {cath }}=\frac{n F D C_{\mathrm{ox}}}{\delta} \pi a^{2}
$$

where $n=4$ is the number of electrons in the oxygen reduction reaction, $F$ is the Faraday constant, $D$ is the $\mathrm{O}_{2}$ diffusion coefficient, $C_{\text {ox }}$ is oxygen concentration, $a$ is the radius of the area covered by the droplet, and $\delta$ is the diffusion layer thickness for $\mathrm{O}_{2}$ in the droplet.

The concentration of oxygen in the electrolyte decreases drastically with time during exposure to the low humidity atmosphere because of a decrease in solubility associated with the increase in magnesium chloride content. Figure 15 shows the oxygen concentration as a function of chloride concentration for $\mathrm{MgCl}_{2}$ solutions from the literature ${ }^{23}$ and also from the dissolved oxygen test kit.

The oxygen diffusivity can be determined from the StokesEinstein equation, which indicates that the diffusion coefficient varies with the inverse of the viscosity. ${ }^{24}$ The viscosity of $\mathrm{MgCl}_{2}$ solutions increases with increasing $\mathrm{MgCl}_{2}$ concentration, ${ }^{25}$ as shown in Fig. 16. Knowing the diffusivity of oxygen in pure water $(2.2$

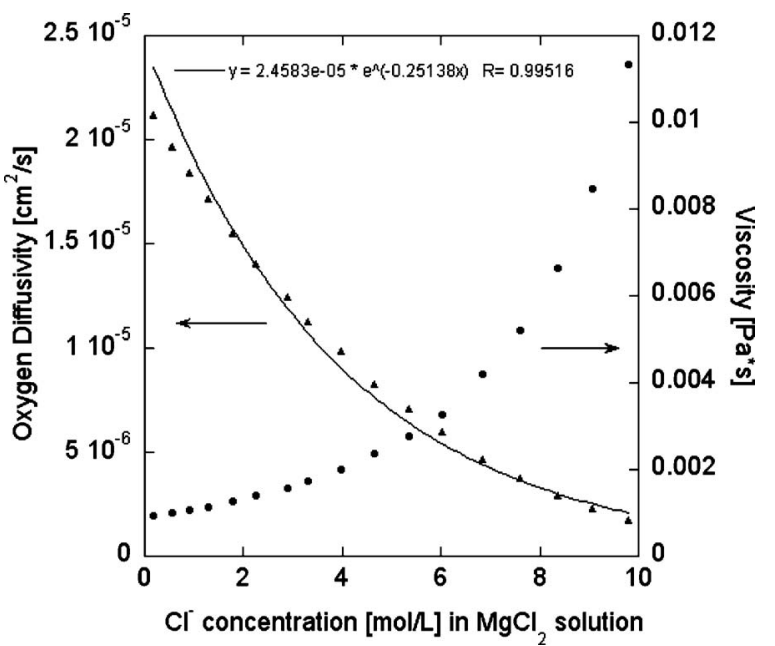

Figure 16. Oxygen diffusivity and viscosity as a function of chloride concentration of $\mathrm{MgCl}_{2}$ solution according to Phang and Stokes. ${ }^{25}$ 
$\left.\times 10^{-5} \mathrm{~cm}^{2} / \mathrm{s}\right),{ }^{26}$ it is possible to calculate the oxygen diffusivity as a function of chloride concentration from the change in viscosity, as is also shown in Fig. 16.

The droplet height $[h(t)]$ was measured by the KP, and the droplet volume was determined from Eq. 1. Knowing the original chloride concentration and the change in droplet volume, the chloride concentration was determined as a function of time from Eq. 2. Finally, the fitted curves in Fig. 15 and 16 were used to determine $C_{\mathrm{ox}}(t)$ and $D(t)$ from the time dependence of the chloride concentration.

Possible errors in the values of oxygen concentration and diffusion coefficient shown in Fig. 15 and 16, respectively, stem from a few sources. The Stokes-Einstein equation describes the motion of spherical particles. Because oxygen as a diatomic molecule does not resemble a sphere, this calculation of diffusivity might be in error. Furthermore, the oxygen concentration and diffusivity were determined based on pure $\mathrm{MgCl}_{2}$ solutions. The stable droplet was shown above to have a lower $\mathrm{MgCl}_{2}$ concentration than expected for a pure $\mathrm{MgCl}_{2}$ solution in equilibrium with the atmospheric $\mathrm{RH}$, which was described to result from the effects of other ions in solution. These ions could affect both the oxygen concentration and diffusion coefficient, as could changes in $\mathrm{pH}$ associated with the corrosion reactions. The oxygen diffusivity and concentration are expected to be lower than the determined values for the pure $\mathrm{MgCl}_{2}$ solutions. Therefore, the results of the following calculation of the cathodic current are likely overestimated.

The last factor required to determine the available cathodic current from Eq. 4 is $\delta$, the diffusion layer thickness. The diffusion layer thickness varied with position and time in the droplet due to the spherical cap shape and evaporation. Assuming one-dimensional (1D) diffusion, the diffusion layer thickness is lower at the drop edge than in the center. Frankel et al. showed that the diffusion limiting current density for oxygen reduction is inversely proportional to the thickness of a thin electrolyte layer for layer thickness between 200 and $10 \mu \mathrm{m} .{ }^{14}$ For a solution layer thickness greater than $200 \mu \mathrm{m}$, natural convection limits the diffusion layer thickness to $200 \mu \mathrm{m}$. For layers thinner than $10 \mu \mathrm{m}$, the transfer of oxygen at the air/electrolyte interface is rate determining. Therefore, the drop was divided into these three regions. For areas in the droplet with a thickness larger than $200 \mu \mathrm{m}$ and smaller than $10 \mu \mathrm{m}, 200$ and $10 \mu \mathrm{m}$ were used as the diffusion layer thickness, respectively. The current for the region of the drop with a height between 200 and $10 \mu \mathrm{m}$ was calculated from the shape of the spherical cap drop according to the details described in the Appendix. Because of the localized nature of the pitting corrosion attack, which focuses the anodic current at the location of the pit, the drop did not behave like a classical Evans drop, which was assumed by Cole et al. who modeled oxygen concentrations in droplets on zinc. ${ }^{27}$

The available cathodic currents in droplets as a function of time were calculated based on the area that the droplet covers, the droplet thickness, and the oxygen concentration and diffusivity as a function of chloride concentration. Figure 17 shows the available cathodic current as a function of time calculated for three different initial droplet volumes with an initial concentration of $0.88 \mathrm{M}$. Also shown in the figure are the chloride concentrations as a function of time, which were used to determine the cathodic currents. The cathodic current is higher for larger drops, particularly at the initial stages of evaporation, because of the larger covered area. The available cathodic current decreases with time because evaporation results in an increase in chloride concentration and thus decreases in the oxygen concentration and diffusivity. The cathodic currents of the three drop sizes converge with time as the oxygen concentration governs the reaction rate. However, the smallest droplet shows the lowest cathodic current. This observation suggests that cathodic limitations might enhance pit repassivation or even inhibit stable pitting as was observed by Tsutsumi et al. ${ }^{6}$

The anodic current demand for a growing pit can be calculated and compared to the available cathodic current. Figure 9 shows the charge associated with the pit volume for pits grown to various

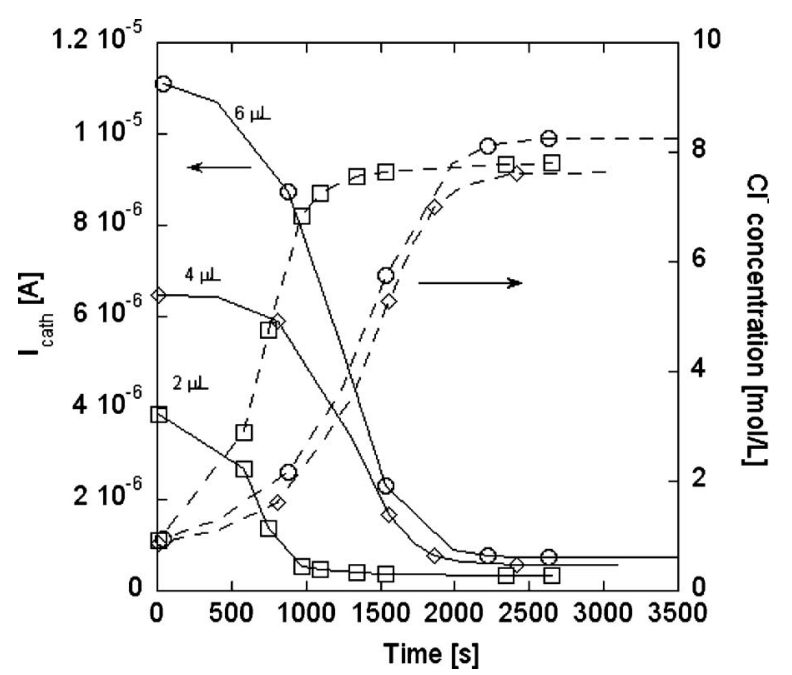

Figure 17. Available cathodic current and chloride concentration as a function of time.

times. The anodic current demand for growing pits can be calculated from the derivative of the charge vs time curves. For droplet volumes of 2 or $4 \mu \mathrm{L}$, the current demand of pits growing at the OCP decrease with time according to these fitted equations

$$
\begin{aligned}
& 2 \mu \mathrm{L}: I=7.18 \times 10^{-7} t^{-0.336} \\
& 4 \mu \mathrm{L}: I=5.97 \times 10^{-7} t^{-0.320}
\end{aligned}
$$

This decrease in pit current with time is in contrast to other papers of increasing pit current with time. ${ }^{28-30}$ The pits in this study grew at the OCP under a thin electrolyte layer, whereas the other involved anodic polarization in bulk solution ${ }^{28,29}$ or exposure to a bulk solution containing oxidizing agents. ${ }^{30}$ Pits in stainless steel formed at high potentials in bulk solution tend to grow deeply into the metal, whereas the pits in the droplet with high chloride concentration were extremely shallow. This geometrical effect controlled the pit current as discussed presently.

To compare the anodic current demands (Eq. 5 and 6) with the available cathodic current, it is necessary to assume a pit initiation time. The available cathodic current starts decreasing immediately upon exposure to the low humidity environment as drying occurs, but the anodic demand only commences with pit initiation. Therefore, the anodic currents in Fig. 18 were offset in time by amounts equal to the mean values of the pitting initiation time for 2 and $4 \mu \mathrm{L}$ droplets shown in Fig. 4, 748 and 1400 s, respectively. Also shown in Fig. 18 are the available cathodic currents from the low current region of Fig. 17. The available cathodic current decreases quickly and then levels off and remains constant. The current demand for a growing pit is smaller than the available cathodic current, which is a requirement for pit stability. This agrees with the observation that repassivation was never observed for any experiment unless the RH was increased as described above. However, the suggestion that pits do not initiate under very small drops due to insufficient cathodic current ${ }^{6}$ cannot be explained by this calculation. The fact that only one pit is always formed under each droplet might be caused by the local cathodic protection of the electrolytecovered metal surface originated by the pit anode. When the entire sample with a surface area of $225 \mathrm{~mm}^{2}$ was immersed in a solution of saturated $\mathrm{MgCl}_{2}$, several pits were observed, which indicates that the throwing power of a pit is enough to protect the drop covered area, but not the entire sample surface in bulk electrolyte. However, the progression of pit morphology described below indicates that cathodic limitation eventually occurred in the small droplets. The 


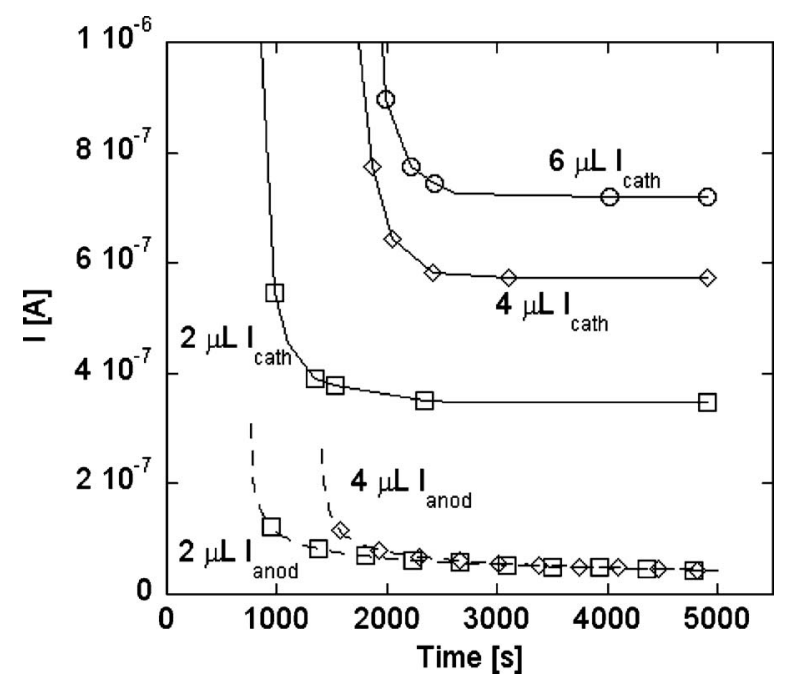

Figure 18. Available cathodic current (solid lines) under droplets of 2, 4, and $6 \mu \mathrm{L}$ and necessary anodic current (dashed lines) for stable pit grows of pits in 2 and $4 \mu \mathrm{L}$ droplets.

calculated available cathodic current is assumed to be an overestimation because of the values used for oxygen concentration and diffusivity.

It is of interest to determine the anodic current density, which can be calculated using the active pit areas shown in Fig. 11. The anodic current density for pits under droplets of an initial volume of $2 \mu \mathrm{L}$ is shown in Fig. 19. The results for the $4 \mu \mathrm{L}$ droplet were very similar. At short pitting times, the anodic current densities varied over a wide range. However, for pitting durations longer than $\sim 160 \mathrm{~min}$, the current density was almost constant at $\sim 6$ $\times 10^{-4} \mathrm{~A} / \mathrm{cm}^{2}$. This value is quite small compared to other reported pit current densities for stainless steels. Szklarska-Smialowska and Janik-Czachor obtained pit current densities between 1 and $2.5 \mathrm{~A} / \mathrm{cm}^{2}$ for a $\mathrm{Fe}-16 \mathrm{Cr}$ alloy in a $0.7 \mathrm{~N} \mathrm{NaCl}$ $+0.7 \mathrm{~N} \mathrm{Na}_{2} \mathrm{SO}_{4}$ solution. ${ }^{31}$ Frankel et al. calculated stable pit current densities between 2 and $4 \mathrm{~A} / \mathrm{cm}^{2}$ for SS302 in different bulk electrolytes. ${ }^{28}$ Pistorius and Burstein reported current densities between 2 and $8 \mathrm{~A} / \mathrm{cm}^{2}$ in a bulk electrolyte with $0.8 \mathrm{M} \mathrm{NaCl}$ and 0.2 $\mathrm{M} \mathrm{HCl}{ }^{32}$ However, all of these results were obtained with pits grown under anodic potential control, not at the OCP, and applied potential can have a large effect on pit current density. ${ }^{28}$

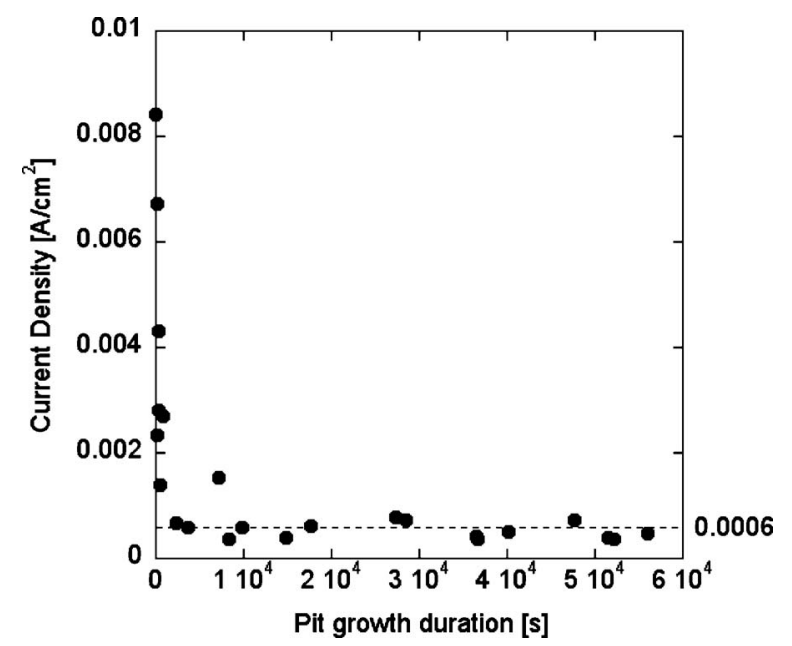

Figure 19. Current density as a function of pitting duration for pits under droplets with an initial volume of $2 \mu \mathrm{L}$.
Knowing the anodic current density, it is possible to calculate the pit stability product $(i d)$, where $d$ is the pit depth or radius. ${ }^{33}$ Pistorius and Burstein found that the critical value of $i d$ for a pit to grow and not repassivate was between 0.3 and $0.6 \mathrm{~A} / \mathrm{m}$ for $\mathrm{SS} 304 .^{32}$ Frankel et al. calculated a critical id value of $0.4 \mathrm{~A} / \mathrm{m} .{ }^{28}$ The necessary pit current density to maintain pit stability is large for a small pit and decreases as the pit grows. Assuming this value of pit stability product is applicable to the pits under droplets observed in this study, the expected pit radius associated with the calculated current density $\left(6 \times 10^{-4} \mathrm{~A} / \mathrm{cm}^{2}\right)$ is $\sim 5 \mathrm{~cm}$, which is orders of magnitude larger than the size of the pits. Clearly, the stability criterion for the pits in this study is much different than for potentiostatically controlled pits at higher potentials in bulk dilute chloride electrolytes. Using a pit radius of $\sim 50 \mu \mathrm{m}$ for the pits under droplets (Fig. 7) and a current density of $6 \times 10^{-4} \mathrm{~A} / \mathrm{cm}^{2}$, the id value is 3 $\times 10^{-6} \mathrm{~A} / \mathrm{cm}$, which is 3 orders of magnitude lower than the values reported previously.

Galvele modeled the transport of ions in a 1D pit geometry. He found a critical value of $i x$ ( $x$ is 1D pit depth) for $\mathrm{pH}$ change inside the pit, which was related to pit stability. ${ }^{33}$ The calculated values of $i x$ for $\mathrm{Fe}, \mathrm{Ni}$, and $\mathrm{Cr}$ were on the order of $10^{-6} \mathrm{~A} / \mathrm{cm}$, which is close to the values determined in this study. However, Galvele calculated the conditions to achieve a metal ion concentration in equilibrium with the metal oxide and arbitrarily used the value of $10^{-6} \mathrm{~mol} / \mathrm{L}$. Today, the ion concentration in a stable pit is known to be considerably higher, namely in the molar region. ${ }^{34}$ The low id value determined in this study results from the lower current density required to stabilize pitting in the concentrated $\mathrm{MgCl}_{2}$ droplet solution, which ends up being similar to that required to achieve a relatively low ion concentration in pits grown in a dilute bulk electrolyte as calculated by Galvele.

Pit growth progression under droplets. - The SEM pictures in Fig. 7 show pits that were grown for different amounts of time. The pits that were only propagated for a short time have a disk-shape appearance with a small hole at the center. Other researchers saw a similar defect and suggested it to be a MnS inclusion, ${ }^{6,8}$ which is a well-known initiation site for pitting corrosion on stainless steel. ${ }^{15-17}$ From the defect, the pits grew uniformly in all directions resulting in circular shapes. Eklund calculated a potential $\mathrm{pH}$ diagram of reactions between $\mathrm{H}_{2} \mathrm{O}, \mathrm{Cl}^{-}$, and $\mathrm{MnS}$. ${ }^{15}$ According to this, $\mathrm{MnS}$ is not thermodynamically stable at an initial OCP between 400 and 300 $\mathrm{mV}$ vs standard hydrogen electrode (Fig. 2) and neutral pH. The predominant species are $\mathrm{Mn}^{2+}$ and $\mathrm{SO}_{4}^{2-}$. Due to an increase in $\mathrm{pH}$ during the formation of these two species, $\mathrm{H}_{2} \mathrm{~S}$ and elemental sulfur can be formed. Hydrogen sulfide was reported to shorten the time to the breakdown of the passive film ${ }^{35}$ and to decrease the pitting potential on SS304 in chloride solution. ${ }^{36}$ The dissolution of MnS leads to sulfur precipitation on the alloy surface adjacent to the inclusion. ${ }^{15,37}$ This adsorbed layer increases the dissolution of the metal due to a decrease in metal/metal bond strength and impedes repassivation. ${ }^{38}$ These observations can be used to explain the circular shape of the pit. Activating S-containing species as well as $\mathrm{H}^{+}$ are transported radially in the thin electrolyte layer, which has a high $\mathrm{Cl}$ concentration. Consequently, a circular area around the initial defect is activated and the active area grows radially and downward slowly at a constant current density. This growth continues until reaching a critical condition. When the current demand exceeds the available cathodic current, the active pit area must decrease to maintain current density on the order of $6 \times 10^{-4} \mathrm{~A} / \mathrm{cm}^{2}$. The decrease in the anodic area is accomplished by partial repassivation and the formation of an active "ear" where the current is focused. Figure $7 b-d$ shows the ear formation for pits grown for different times. Figure 11 reflects this behavior in a slight decrease in the active area with increasing pitting time. Careful observation of a series of pits indicated that a depression inside the disk started forming between 90 and 100 min after the initiation of pitting under $2 \mu \mathrm{L}$ droplets 
and between 130 and 140 min under $4 \mu \mathrm{L}$ drops. Thus, critical conditions are reached earlier under smaller drops than under larger ones.

\section{Conclusions}

In this study, the pitting corrosion behavior of SS304 under an evaporating electrolyte droplet was investigated with a KP. The effect of the drop size and concentration on the pit initiation time and initiation chloride concentration was determined. The following was found:

1. Pits initiated sooner under small droplets than under large drops because of a faster evaporation rate and a steeper increase in the chloride concentration during drying.

2. The initiation chloride concentration was between 3.0 and 8.4 $\mathrm{M}$ for droplets with a starting concentration of $0.88 \mathrm{M} \mathrm{Cl}^{-}$. The pitting initiation concentration was higher for drops with a higher starting concentration.

3. The probability of pitting at a lower chloride concentration was higher under a large drop than under a small drop, possibly because of the larger electrolyte-covered area and therefore a higher probability of covering a more susceptible defect. No relationship was found between the drop height and the critical chloride concentration.

4. Available cathodic current decreases with time. Required anodic current is less than the calculated cathodic current. However, several observations indicate cathodic limited pit growth.

5. Pit stability criterion (id) is much lower than for potentiostatically controlled pits in dilute bulk chloride solutions.

6. Pits under droplets first grow in the lateral direction away from a defect forming a disk. Then pitting continues inside the disk in a confined area leading to an ear-shaped hole.

\section{Acknowledgment}

Support by the Science \& Technology Program of the Office of the Chief Scientist (OCS), Office of Civilian Radioactive Waste Management (OCRWM), U.S. Department of Energy (DOE) is gratefully acknowledged. The work was performed under the Corrosion and Materials Performance Cooperative, DOE cooperative agreement no. DE-FC28-04RW12252.

The Ohio State University assisted in meeting the publication costs of this article.

\section{Appendix}

Assuming the droplet takes the shape of a spherical cap, the cross section of a droplet through the center resembles a circular segment with the height $h$ (drop height), the radius of the circle $R$, the chord length $l$, which is the diameter of the drop ( $2 a)$, and an angle $\alpha$ (Fig. A-1). A circle with the center at $(b, c)$ in a Cartesian coordinate system is represented by the following equation

$$
(x-b)^{2}+(y-c)^{2}=R^{2}
$$

The center of the circle is at $(0, h-R)$. Therefore

$$
\begin{gathered}
\xi^{2}+[\eta-(h-R)]^{2}=R^{2} \\
\eta=\sqrt{R^{2}-\xi^{2}}+(h-R)
\end{gathered}
$$

where $\xi$ and $\eta$ are the $x$ and $y$ coordinates along the circular section

The available cathodic current can be calculated from

$$
I=\frac{n F D C_{\mathrm{ox}}}{\delta(x)} A=c \frac{A}{\delta(x)}
$$

where $c=n F D C_{\mathrm{ox}}, n=4$ is the number of electrons in the oxygen reduction reaction, $F$ is the Faraday constant, $D$ is the diffusion coefficient of oxygen, $C_{\mathrm{ox}}$ is oxygen concentration, $A$ is the area covered by the droplet, and $\delta$ is the diffusion layer thickness for $\mathrm{O}_{2}$ in the droplet. The diffusion layer thickness is divided into three regimes

$$
\begin{gathered}
\text { for } \eta>200 \mu \mathrm{m} \quad \delta=200 \mu \mathrm{m} \\
\text { for } 10 \mu \mathrm{m}>\eta>200 \mu \mathrm{m} \quad \delta=\sqrt{R^{2}-x^{2}}+(h-R)
\end{gathered}
$$

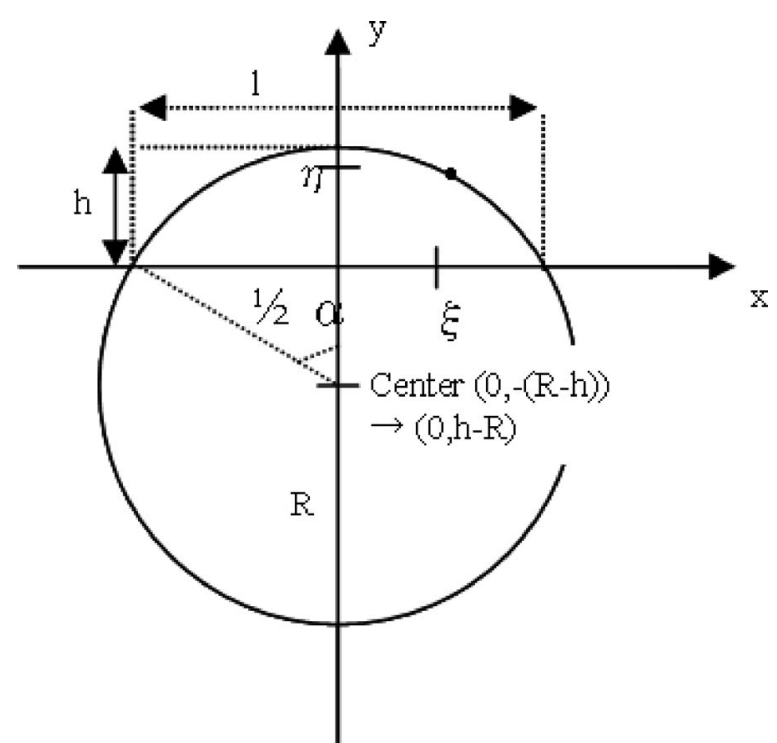

Figure A-1. Side-view of droplet showing geometry of circular segment.

$$
\text { for } \eta<10 \mu \mathrm{m} \quad \delta=10 \mu \mathrm{m}
$$

In regions where the droplet is thicker than $200 \mu \mathrm{m}, \delta$ is assumed to be $200 \mu \mathrm{m}$, and in regions where the droplet is less than $10 \mu \mathrm{m}$ thick, $\delta$ is assumed to be $10 \mu \mathrm{m}$. The current can be calculated by summing the contributions from these three regions

$$
I=\frac{c}{200 \mu \mathrm{m}} \pi r_{1}^{2}+c \int_{r_{1}}^{r_{2}} \frac{d A}{\delta(r)}+\frac{c}{10 \mu \mathrm{m}} \pi\left(a^{2}-r_{2}^{2}\right)
$$

where $r_{1}$ is the radius at which $\eta=200 \mu \mathrm{m}$ and $r_{2}$ is the radius at which $\eta$ $=10 \mu \mathrm{m}$. It is necessary to calculate these radii, which was done using geometrical considerations. The current for the region where $10 \mu \mathrm{m}>\eta>200 \mu \mathrm{m}$ can be calculated by integrating across the droplet area

$$
I_{10-200}=c \int \frac{d A}{\delta(x)} d x
$$

The droplet area is given by

$$
A=\pi x^{2}
$$

which can be differentiated for later integration

$$
d A=2 \pi x d x
$$

Therefore, the total available cathodic current is given by

$$
I=\frac{c}{200 \mu \mathrm{m}} \pi r_{1}^{2}+c \int_{r_{1}}^{r_{2}} \frac{2 \pi x}{\sqrt{R^{2}-x^{2}}+(h-R)} d x+\frac{c}{10 \mu \mathrm{m}} \pi\left(a^{2}-r_{2}^{2}\right)
$$

The second term on the right side of Eq. A-9 was determined by numerical integration to result in the total available cathodic current shown in Fig. 16.

\section{References}

1. H. P. Leckie and H. H. Uhlig, J. Electrochem. Soc., 113, 1262 (1966).

2. N. J. Laycock and R. C. Newman, Corros. Sci., 39, 1771 (1997).

3. R. P. Vera Cruz, A. Nishikata, and T. Tsuru, Corros. Sci., 40, 125 (1998)

4. S. Ito, M. Yabumoto, H. Omata, and T. Murata, in Passivity of Metal and Semiconductors, Proceedings of the 5th International Symposium, p. 637 (1983).

5. Y. Tsutsumi, A. Nishikata, and T. Tsuru, J. Electrochem. Soc., 153, B278 (2006)

6. Y. Tsutsumi, A. Nishikata, and T. Tsuru, Corros. Sci., 49, 1394 (2007).

7. Y. Tsutsumi, A. Nishikata, and T. Tsuru, J. Electrochem. Soc., 152, B358 (2005).

8. S. Hastuty, A. Nishikata, and T. Tsuru, Corros. Sci., 52, 2035 (2010).

9. R. P. Vera Cruz, A. Nishikata, and T. Tsuru, Corros. Sci., 38, 1397 (1996).

10. A. Nishikata, Y. Ichihara, and T. Tsuru, Corros. Sci., 37, 897 (1995).

11. M. Stratmann and H. Streckel, Corros. Sci., 30, 697 (1990).

12. M. Stratmann and H. Streckel, Corros. Sci, 30, 681 (1990).

13. M. Stratmann, H. Streckel, K. T. Kim, and S. Crockett, Corros. Sci., 30, 715 (1990).

14. G. S. Frankel, M. Stratmann, M. Rohwerder, A. Michalik, B. Maier, J. Dora, and M. Wicinski, Corros. Sci., 49, 2021 (2007).

15. G. Eklund, J. Electrochem. Soc., 121, 467 (1974).

16. Z. Szklarska-Smialowska, Corrosion (Houston), 28, 389 (1972).

17. G. Wranglen, Corros. Sci., 14, 331 (1974). 
18. R. C. Weast, in CRC Handbook of Chemistry and Physics, CRC Press, Boca Raton, FL (1980).

19. S. Turgoose, Studies in Conservation, 27, 97 (1982)

20. D. Watkinson and M. Lewis, in Proceedings of Metal 2004, National Museum of Australia Canberra ACT, 4-8 October, p. 88 (2004)

21. F. Hunkeler and H. Boehni, in Passivity of Metals and Semiconductors, Proceedings of the 5th International Symposium, p. 655 (1983).

22. I. L. Rosenfeld and I. S. Danilov, Z. Phys. Chem., 226, 257 (1964).

23. C. G. MacArthur, J. Phys. Chem., 20, 495 (1916).

24. P. R. Roberge, Handbook of Corrosion Engineering, McGraw-Hill, New York (2000).

25. S. Phang and R. H. Stokes, J. Solution Chem., 9, 497 (1980).

26. B. Case, Electrochim. Acta, 18, 293 (1973).

27. I. S. Cole, N. S. Azmat, A. Kanta, and M. Venkatraman, Int. Mater. Rev., 54, 117 (2009).
28. G. S. Frankel, L. Stockert, F. Hunkeler, and H. Boehni, Corrosion (Houston), 43, 429 (1987).

29. R. C. Newman and E. M. Franz, Corrosion (Houston), 40, 325 (1984).

30. I. L. Rosenfeld and I. S. Danilov, Corros. Sci., 7, 129 (1967).

31. Z. Szklarska-Smialowska and M. Janik-Czachor, Br. Corros. J., London, 4, 138 (1969).

32. P. C. Pistorius and G. T. Burstein, Philos. Trans. R. Soc. London, Ser. A, 341, 531 (1992).

33. J. R. Galvele, J. Electrochem. Soc., 123, 464 (1976).

34. R. C. Newman, Electrochem. Soc. Interface, 19, 33 (2010).

35. C. S. Brossia and R. G. Kelly, Corros. Sci., 40, 1851 (1998).

36. R. C. Newman, H. S. Isaacs, and B. Alman, Corrosion (Houston), 38, 261 (1982).

37. J. E. Castle and R. Ke, Corros. Sci., 30, 409 (1990).

38. P. Marcus, J. Chim. Phys. Phys.- Chim. Biol., 88, 1697 (1991). 